\title{
Investigation of The Capacitive Behavior of Polyluminol on Carbon Nanotubes Electrodes
}

N'Diaye, Jeanne; Chang, Jin Hyun; Lian, Keryn

Published in:

ChemElectroChem

Link to article, DOI:

10.1002/celc.201901473

Publication date:

2019

Document Version

Peer reviewed version

Link back to DTU Orbit

Citation (APA):

N'Diaye, J., Chang, J. H., \& Lian, K. (2019). Investigation of The Capacitive Behavior of Polyluminol on Carbon Nanotubes Electrodes. ChemElectroChem, 6(21), 5454-5461. https://doi.org/10.1002/celc.201901473

\section{General rights}

Copyright and moral rights for the publications made accessible in the public portal are retained by the authors and/or other copyright owners and it is a condition of accessing publications that users recognise and abide by the legal requirements associated with these rights.

- Users may download and print one copy of any publication from the public portal for the purpose of private study or research.

- You may not further distribute the material or use it for any profit-making activity or commercial gain

- You may freely distribute the URL identifying the publication in the public portal 


\section{FUNDAMENTALS \& APPLICATIONS \\ CHEMELECTROCHEM}

ANALYSIS \& CATALYSIS, BIO \& NANO, ENERGY \& MORE

\section{Accepted Article}

Title: Investigation of The Capacitive Behavior of Polyluminol on Carbon Nanotubes Electrodes

Authors: Jeanne N'Diaye, JinHyun Chang, and Keryn Lian

This manuscript has been accepted after peer review and appears as an Accepted Article online prior to editing, proofing, and formal publication of the final Version of Record (VoR). This work is currently citable by using the Digital Object Identifier (DOI) given below. The VoR will be published online in Early View as soon as possible and may be different to this Accepted Article as a result of editing. Readers should obtain the VoR from the journal website shown below when it is published to ensure accuracy of information. The authors are responsible for the content of this Accepted Article.

To be cited as: ChemElectroChem 10.1002/celc.201901473

Link to VoR: http://dx.doi.org/10.1002/celc.201901473 


\title{
Investigation of The Capacitive Behavior of Polyluminol on Carbon Nanotubes Electrodes
}

\author{
Jeanne N'Diaye, ${ }^{[a]^{\star}}$ Jin Hyun Chang, ${ }^{[\mathrm{b}]}$ and Keryn Lian ${ }^{[a]}$
}

\begin{abstract}
A polymerized luminol carbon nanotube (CNT) composite electrode was developed via an in-situ chemical polymerization (CpLum) process. Density functional theory (DFT) simulation suggested the luminol molecules were preferentially aligned flat on CNT. This was further demonstrated by morphological study which showed the CpLum wrapped around each CNT tube homogeneously with an average thickness of $4.5 \pm 1.5 \mathrm{~nm}$. The surface chemical analysis by X-ray photoelectron spectroscopy (XPS) revealed a progressive increase in the nitrogen content and stabilized at $9 \%$. Deconvolution of the high-resolution N1s spectra suggested the presence of secondary and tertiary amine functional groups which are the signatures of polymerized luminol. The composite electrodes exhibited a pseudocapacitive-like behavior with 3.5 times increase in charge storage. The contributions from the CpLum coating and CNT substrate were differentiated and were further deconvoluted to quantify the capacitive charge storage of each component. The thin CpLum coating contributed $70 \%$ of the total charge storage through pseudocapacitance. CpLum-CNT electrodes also showed a high rate capability and good cycling stability, very promising for electrochemical capacitors.
\end{abstract}

\section{Introduction}

Carbon-polymer composites electrodes have demonstrated promising properties for electrochemical capacitors (ECs). In these composites, carbon provides high surface area, good electrical conductivity and high stability [1], while the electrochemically active polymers add enhanced pseudocapacitive charge storage capabilities [2]. Various fabrication methods have been developed for carbon-polymer composites such as layer-by-layer deposition, electropolymerization and in-situ polymerization ${ }^{[3]}$, enabling a good control over the structure and thickness of the polymer coating ${ }^{[4]}$. In-situ polymerization is widely used to modify the surface of carbon nanostructures ${ }^{[5]}$. This technique is especially attractive as it not only possesses the aforementioned advantages but also can be more economical and practical for large scale electrode fabrication ${ }^{[6]}$.

Luminol, an electroactive organic compound, was reported for applications in sensors, signal amplification, and electrochemiluminescence [7]. This molecule exhibited electrochemical redox activity when polymerized and deposited

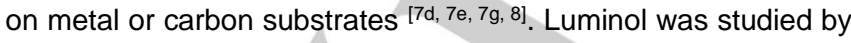
electropolymerization on graphene for ECs and showed similar

[a] J. N'Diaye, Prof K. Lian

Materials Science and Engineering

University of Toronto

184 College St, Toronto, Ontario, M5S 3E4, Canada

E-mail: Jeanne.ndiaye@mail.utoronto.ca, keryn.lian@utoronto.ca

[b] J. H. Chang

Department of Energy Conversion and Storage

Technical University of Denmark

DK-2800 Kgs. Lyngby, Denmark Address 2

E-mail: jchang@dtu.dk

Supporting information for this article is given via a link at the end of the document. performance to other graphene-polymer composites [3a]. It is also of interest to develop a polyluminol-carbon composite via the chemical approach. In addition to deposition methods, there are other questions regarding the carbon-polyluminol interactions and the controlling mechanisms in pseudocapacitive charge storage within the composites that should be investigated.

It has been well accepted that both surface- and diffusioncontrolled processes are involved in most of the pseudocapacitive processes. The quantification of these two has been utilized for many nanosized metal oxide electrodes that store charge via intercalation pseudocapacitance ${ }^{[9]}$. Such quantification method may also be applicable to polymer-carbon composites. Since most conductive polymers grow on carbon and metal substrates, it is difficult to differentiate the capacitive and diffusion-controlled contribution from the entire charge storage process. Therefore, leveraging the existing approach to deconvolute the contribution not only from different processes but also from each component within the composite will also be necessary and useful from a materials development and characterization standpoint.

In this work, a composite electrode material based on chemically polymerized luminol modified carbon nanotube (CpLum-CNT) was investigated and compared to its CNT baseline (Figure 1). The objectives are, a) to understand the structural and chemical properties of the polymer-CNT, as well as the interactions between the luminol and CNT, b) to investigate the electrochemical behavior of the CpLum-CNT electrodes, and c) to deconvolute the capacitive contributions of each component within the composite and determine the pseudocapacitive contribution of the polyluminol at different rate.

\section{Luminol}

$(0.35 \mathrm{~g})$

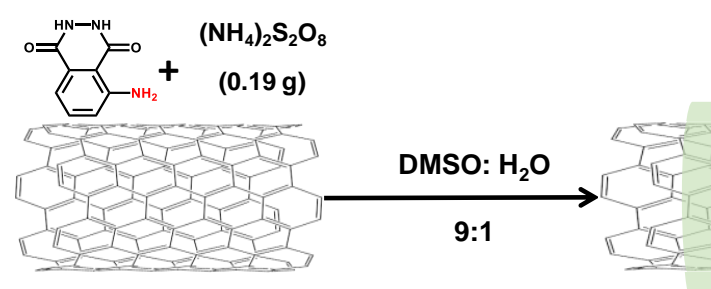

Figure 1. Schematic of the in-situ polymerization process of luminol on CNT using an oxidative polymerization reaction.

\section{Results and Discussion}

The surface morphology of the modified CNT films was studied at various polymerization time and compared to the bare CNT. The CpLum-CNT composites were characterized using SEM, Raman, XPS, and CV. Figures 2a) and S1) show the SEM micrographs of bare CNT and CpLum-CNT after 15, 60, and $180 \mathrm{~min}$ of polymerization. An increase in tube diameter was observed with reaction time in all SEM micrographs. The low magnification SEM micrographs appeared relatively clean without additional features, while the high-resolution micrographs showed that CpLum grew 
and wrapped around the individual CNT after polymerization (Figure S1). Compared to bare CNT which had an average tube diameter of $23 \mathrm{~nm} \pm 4 \mathrm{~nm}$, the diameters of CpLum-CNT were increased to $29 \mathrm{~nm} \pm 6 \mathrm{~nm}, 32 \mathrm{~nm} \pm 7 \mathrm{~nm}$, and $32 \mathrm{~nm} \pm 7 \mathrm{~nm}$ after 15,60 , and $180 \mathrm{~min}$ of polymerization, respectively (Figure $\mathbf{2 b}$ )). The diameter of CpLum-CNT was stabilized with a polymer thickness of $4.5 \mathrm{~nm} \pm 1.5 \mathrm{~nm}$ after 60 min of reaction.

The DFT calculation was conducted to visualize the starting point of polymer deposition via monomer orientation on the substrate as well as to understand the carbon-organic layer interactions (Figure 2c, Figure S2). The orientation in which the luminol preferred to adsorb onto the graphene was assessed by computing its adsorption energy, $E_{a d s}$, which is defined in Eq. (1) as:

$$
E_{\text {ads }}=E_{\text {gr/luminol }}-E_{g r}-E_{\text {luminol }}
$$

where $E_{g r / l u m i n o l} E_{g r}$, and $E_{\text {luminol }}$ refer to the total DFT energy of the system consisting of both graphene and luminol, only of graphene and only of luminol, respectively. The $E_{\text {ads }}$ was calculated for luminol adsorbed in six different orientations: two adsorbed horizontally on to the surface and four adsorbed vertically on to the surface. The final adsorbed geometries of the six considered orientations and their computed adsorption energies are illustrated in Figure S2. The horizontal orientation was related to the monomer laying and facing the graphene. The vertical orientation represented the monomer laying sideways on the graphene. The adsorption energies in Figure $\mathbf{S} 2$ were all negative values, indicating that it was energetically preferable for luminol to be adsorbed on the CNT. One distinct feature that can be observed from Figure $\mathbf{S} 2$ was that the magnitudes of $E_{\text {ads }}$ for luminol adsorbed in horizontal orientations were roughly $0.5 \mathrm{eV}$ higher than those adsorbed in vertical orientations for both oneand two-layer graphene. The Eads of luminol is roughly $0.5 \mathrm{eV}$ higher in magnitude when adsorbed in a horizontal orientation compared to a vertical orientation. The maximum deviation of $E_{a d s}$ among the two horizontal and four vertical orientations considered is $0.08 \mathrm{eV}$ (see Figure S2), which is substantially smaller than the $0.5 \mathrm{eV}$ difference. Such observation suggested that luminol monomers before being polymerized on carbon preferred to adsorb in a horizontal orientation.

The DFT analysis and SEM micrograph gave evidence on the deposition process prior to and after in-situ polymerization. DFT also revealed that the luminol monomer preferred a horizontal orientation. Once the polymerization is initiated, the polymer chains were likely grown and wrapped along the CNT until reaching a saturated thickness.

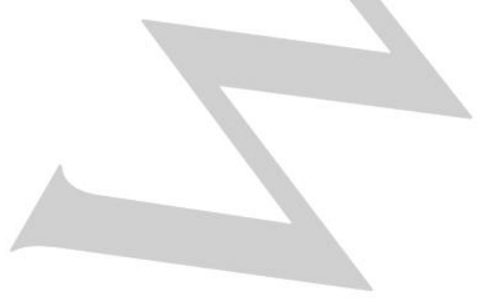

(a)

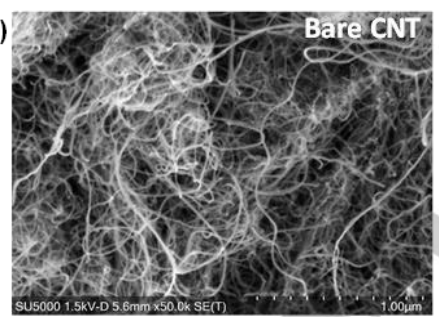

(b)
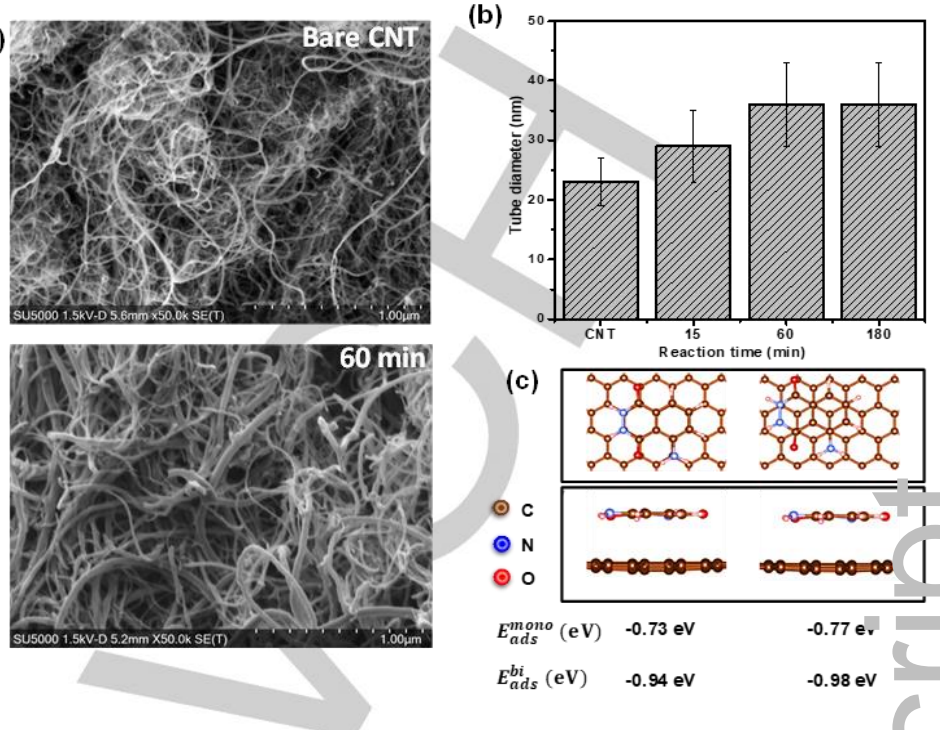

(c)

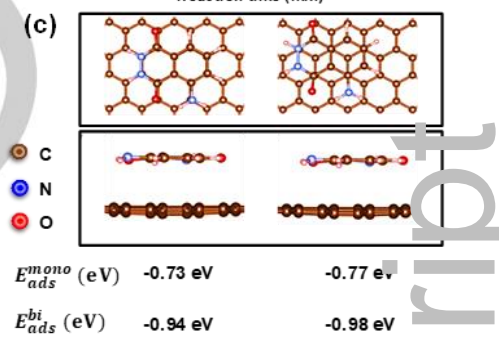

$E_{\text {ads }}^{b i}(\mathrm{eV}) \quad-0.94 \mathrm{eV}$

Figure 2. a) Scanning electron micrograph of bare, and CpLum-CNT after 60 min of reaction, b) chart of tube diameter at various reaction time, and c) DFT calculation of the top and side view of the horizontal orientations of luminol with their adsorption energies.

The carbon-polymer interactions were further investigated using Raman and XPS spectroscopies (Figure 3). Raman spectroscopy analyses were conducted to identify changes within the carbon structure, particularly the degree of disorder introduced during the polymerization. The Raman spectra of bare CNT and the modified CNT films are shown in Figure 3a). Although the SEM micrograph in Figure 2a) provided strong evidence of polymer deposition on the tubes, all the spectra showed typical D, G, and 2D bands for carbon-based materials ${ }^{[14]}$. The lack of polymer related Raman signature might be due to the nanometer-scale polymer layer on the surface, which did not disrupt the $\pi-\pi$ conjugated system of CNT ${ }^{[14]}$. Since the polymer layer is very thin, it might be beyond the detection limit of the instrument. The only indication of the presence of the polymer is a slight shift of the Raman bands toward lower wavenumbers. The $D$ and $G$ band for CNT at 1341 and $1574 \mathrm{~cm}^{-1}$ were shifted to 1335 and $1567 \mathrm{~cm}^{-1}$ for CpLum-CNT. This shift of the D and G band is possibly due to the stacking of the CpLum layer on CNT [15].

XPS analysis was performed on both CpLum-CNT and bare CNT to confirm the chemical nature of the deposited polymer. The XPS survey spectra are depicted in Figure $3 \mathbf{b}$ ), which exhibited a progressive increase of $\mathrm{O} 1 \mathrm{~s}$ and $\mathrm{N} 1 \mathrm{~s}$ over the polymerization time. This increase of O1s N1s supports the successful surface modification of CNT with CpLum that had nitrogen and oxygen functionalities. The primary elemental composition of the modified films was tracked for $\mathrm{C} 1 \mathrm{~s}, \mathrm{~N} 1 \mathrm{~s}$ and $\mathrm{O} 1 \mathrm{~s}$, which are summarized in Table 1. The N1s signal increased and stabilized at about $9 \%$ between 60 and $180 \mathrm{~min}$ of reaction. The O1s percentage also increased and plateaued at $8 \%$. The elemental percentage of the C1s peak decreased slightly after the deposition of CpLum on 
CNT. These results complemented the findings in Figure 2 and 3a), and suggested that $60 \mathrm{~min}$ of reaction is adequate to achieve uniform coverage of the nanotubes without disrupting carbon $\mathrm{Sp}^{2}$ conjugated system.

(a)
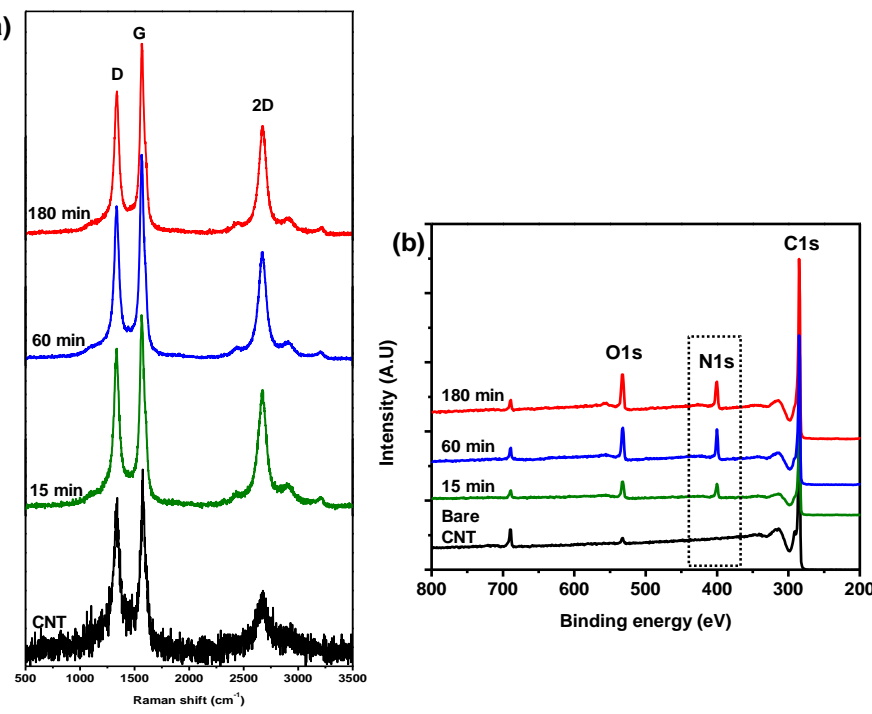

Figure 3. a) Raman pattern and b) XPS survey of bare CNT and CpLum-CNT for reaction times of 15,60 , and $180 \mathrm{~min}$.

Table 1. Values of the elemental percentage of $\mathrm{C} 1 \mathrm{~s}, \mathrm{~N} 1 \mathrm{~s}$, and $\mathrm{O} 1 \mathrm{~s}$

\begin{tabular}{cccc}
\hline $\begin{array}{c}\text { Reaction time } \\
(\mathrm{min})\end{array}$ & C1s [\%] & N1s [\%] & O1s [\%] \\
\hline 0 & 95.85 & 0 & 1.85 \\
15 & 82.17 & 8.03 & 7.33 \\
60 & 80.52 & 9.62 & 8.06 \\
180 & 81.07 & 9.06 & 8.25 \\
\hline
\end{tabular}

The chemical composition of CpLum polymer was previously investigated using XPS spectroscopy. The high-resolution N1s peak revealed a signature peak at $398.98 \mathrm{eV}$, corresponding to the formation of tertiary amine groups within the polymer structure [16]. The chemical conformation of the CpLum on CNT was confirmed through its high-resolution $\mathrm{C} 1 \mathrm{~s}, \mathrm{~N} 1 \mathrm{~s}$, and $\mathrm{O} 1 \mathrm{~s}$ spectra (Figure 4, Figure S3). In the C1s peak of CpLum-CNT, multiple subpeaks were located at $284.4 \mathrm{eV}(\mathrm{C}=\mathrm{C}), 285.4 \mathrm{eV}(\mathrm{C}-\mathrm{C} / \mathrm{C}-\mathrm{N})$, $286.3 \mathrm{eV}(\mathrm{C}-\mathrm{O}), 287.5 \mathrm{eV}(\mathrm{C}=\mathrm{O}), 288.5 \mathrm{eV}(\mathrm{O}-\mathrm{C}=\mathrm{O})$, and 291.3 $\mathrm{eV}(\mathrm{C}-\mathrm{F})$ as shown in Figure $\mathbf{4 a}$ and $\mathbf{b})$. The peak at 285.4 representing $\mathrm{C}-\mathrm{N}$ was the result of the secondary amine functionalities formed within the polymer structure. Such functionalities are characteristics of the nitrogen that bonded to the benzoid $(\mathrm{Bz})$ and quinoid $(\mathrm{Q})$ rings (as seen in Figure 5) ${ }^{[16-}$ 17]. The N1s peak (Figure 4c)) provided additional evidence to the existence of such functionalities. Three subpeaks were obtained and were related to $=\mathrm{N}$ - bonded to $\mathrm{Q}(399 \mathrm{eV}), \mathrm{NH}$ attached to the $\mathrm{Bz}(400 \mathrm{eV})$, and $\mathrm{O}=\mathrm{C}-\mathrm{NH}$ from the phtalazinedione group $(401 \mathrm{eV})^{[7 a, 7 b, 18]}$. The presence of the tertiary amine group $(-\mathrm{N}=)$ that bonded to $Q$ rings agrees with the previous study, which reported the formation of benzoid and quinoid segments within CpLum ${ }^{[16]}$. In addition to the $\mathrm{C} 1 \mathrm{~s}$ and N1s, the shape of the $\mathrm{O} 1 \mathrm{~s}$ peak revealed that the oxygen functionalities on the CNT surface changed from a single peak to a doublet peak for the composite, due to the carbonyl groups within the polymer (Figure S3 and Figure 5) ${ }^{[16]}$.
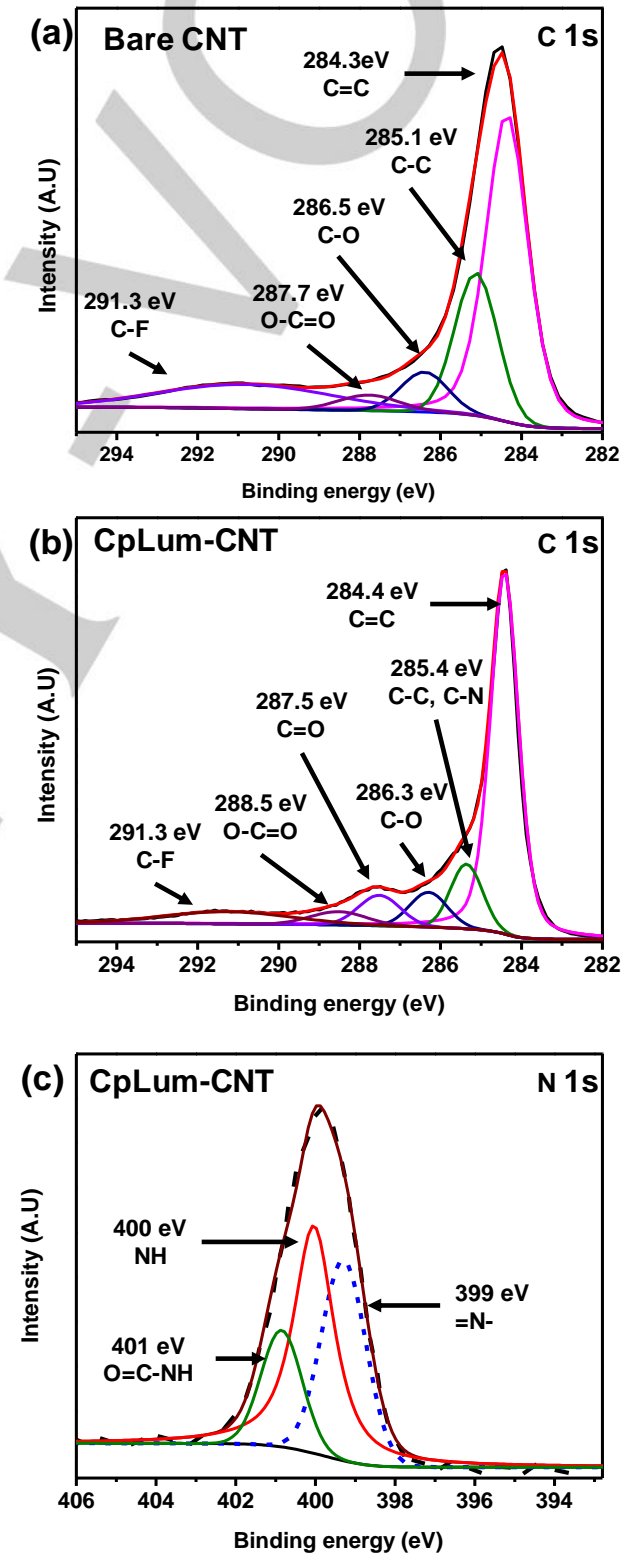

Figure 4. $a$ and b) High resolution XPS C1s for bare CNT and CpLum-CNT, and c) N1s spectra for CpLum-CNT. 


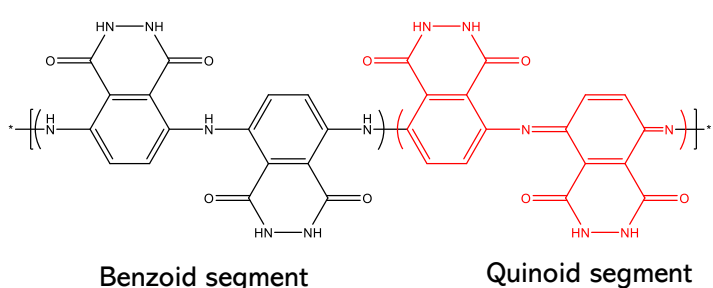

Figure 5. Benzoid and quinoid segments within CpLum.

In Figure 2, the thickness of CpLum on CNT reached a plateau after $60 \mathrm{~min}$ of polymerization. The $\mathrm{CV}$ of each composite electrode was obtained and compared to that of bare CNT (Figure 6) to correlate the deposition time and coating thickness with the charge storage. The CV profiles of bare CNT and CpLumCNT after 15, 60, and 180 min of reaction are overlaid in Figure 6a). The CV of bare CNT had a near rectangular shape typical of a capacitive behavior, while the composite electrodes showed an increased current over the potential range with oxidation peaks at $0.36,0.46$, and $0.64 \mathrm{~V}$, and the most apparent reduction peaks at 0.31 , and $0.54 \mathrm{~V}$. The amount of charge stored was increased by 3.5 times after $60 \mathrm{~min}$ of reaction (Figure $6 \mathrm{~b}$ )). The multiple redox peaks and the increase in charge implied that the CpLum-CNT electrode exhibited pseudocapacitive-like behavior. Adding a thin polymer layer greatly modified the surface chemistry of CNT and led to a significant increase in charge storage.
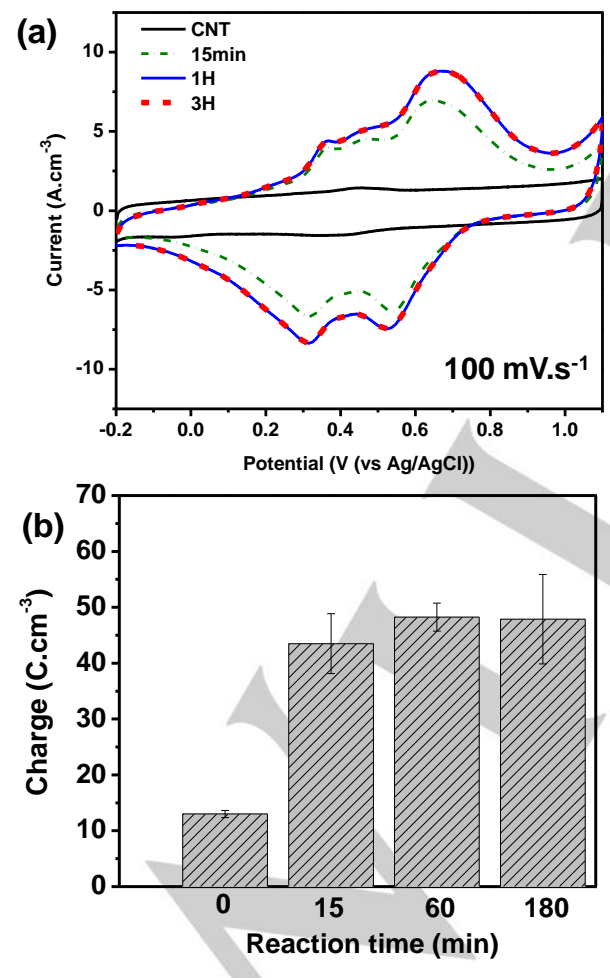

Figure 6. a) CV profile and b) total charge stored for bare and CpLum-CNT after 15,60 , and $180 \mathrm{~min}$ of reaction.
Although the CV profiles of the CpLum-CNT were not rectangular like CNT, they showed some reversible peaks. To identify the capacitive contribution of CpLum on CNT, the current response of the composite electrode was measured at various scan rates (Figure 7), from $15 \mathrm{mV} . \mathrm{s}^{-1}$ to $1 \mathrm{~V} . \mathrm{s}^{-1}$ (Figure 7a)). As proposed by Dunn et al., it is possible to quantify the dominating charge storage mechanism of the composite electrode by deconvoluting the current response at a fixed potential into either diffusioncontrolled or surface capacitive controlled processes [19]. This approach was employed to analyze the contribution of these two processes for CpLum-CNT composite as well.

According to Eq. (2), the measured current, $i$, is related to the scan rate $(U)$ via

$$
i=a \mathrm{U}^{b}
$$

Where parameter $\mathrm{b}$ is the slope of the plot of $\log (i)$ vs $\log (U)$ (Figure S4a)), and gives information regarding the charge storage mechanism. The $b$-value, which has two implications: if $b$ is between 0.5 and 0.8 , the charge storage process is diffusioncontrolled, if $\mathrm{b}$ is between 0.8 and 1 , the storage process is mostly surface capacitive dominated.

The b-values at several potentials (see arrows in Figure 7a)) were extrapolated using E.q. (2) (Figure 7b)). The CpLum-CNT composite electrode had $b$-values between 0.8 and 1 over the potential range, indicating a mostly capacitive behavior even at potentials of $0.36,0.46$, and $0.64 \mathrm{~V}$, where the redox reactions occurred (Figure 7a)). This implied that the redox response of the CpLum -CNT composite was governed by a relative fast capacitive charge storage mechanism originating from pseudocapacitance and double-layer capacitance. a)

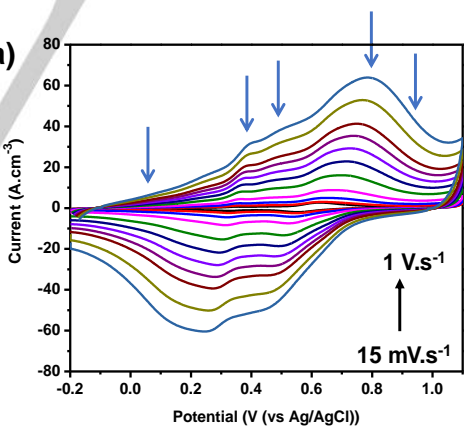

(b)

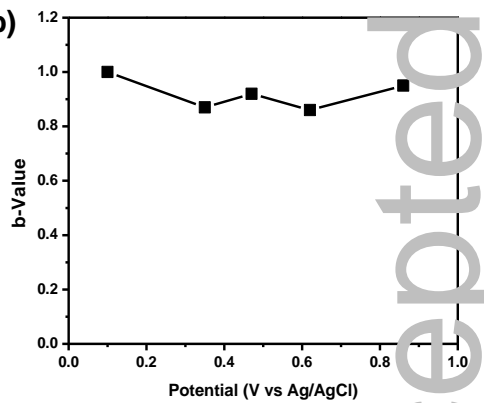

Figure 7. a,b) CV profile of CpLum-CNT composite electrode at various scan rates, and b-values over the studied potential range.

The capacitive contribution can be further quantified over the entire potential range using Eq. (3),

$$
i(V)=k_{1} \mathrm{U}+k_{2} \mathrm{U}^{1 / 2}
$$

where $k_{1} U$ and $k_{2} U^{1 / 2}$ represent the respective capacitive and diffusion-controlled contributions of the total current. Examples of the extrapolated curves can be found in Figure S4b) ${ }^{[9 b, 19] .}$ 
The CV profile of CpLum-CNT was deconvoluted into capacitive and diffusion-controlled processes at $15 \mathrm{mV} . \mathrm{s}^{-1}$ and $100 \mathrm{mV} . \mathrm{s}^{-1}$ (Figure 8). The shaded area reflects the charge stored and delivered from the capacitive process and the remaining area is the diffusion-controlled portion. At a slower scan rate of $15 \mathrm{mV} . \mathrm{s}$ 1, CpLum-CNT had a total stored charge of $73{\mathrm{C} . \mathrm{cm}^{-3}}^{3}$. The capacitive contribution was estimated to be $74 \%$ (or 54 C.cm ${ }^{-3}$ ) of the total charge (Table 2 and Figure $8 \mathrm{a}$ )). When the scan rate was increased to $100 \mathrm{mV} . \mathrm{s}^{-1}$, the amount of charge decreased to $51{\mathrm{C} . \mathrm{cm}^{-3}}^{-3}$ with a capacitive contribution of $89 \%\left(45{\left.\mathrm{C} . \mathrm{cm}^{-3}\right)}^{-3}\right.$ (Figure $\mathbf{8 b}$ )). The greater charge at the slow scan rate was due to the high accessibility of ions and the completion of the redox reaction. The high ratio of capacitive contribution at higher rate reflected the fast-electrochemical response of the composite electrode, and agreed with the obtained b-values (Figure 7b)). The increase of the relative capacitive contribution at higher scan rate also signified the good rate capability of the composite.

The capacitive contribution of the CNT electrode was also analyzed using the same methodology (Table 2 and Figure S5). Although CNT is very capacitive in nature, at slow scan rate the capacitive contribution was only about $78 \%\left(17 \mathrm{C} . \mathrm{cm}^{-3}\right)$ of the total charge. At higher rate, CNT had $90 \%$ of capacitive current. Adding CpLum did increase the current as expected; however the impact of such increase should be assessed to understand the effect of CpLum.

It should be noted that the capacitive contribution from Eq. (2) and (3) is a combination of both EDLC and pseudocapacitance for the CpLum-CNT. To extract and quantify the contribution from the polymer layer, the capacitive and diffusion-controlled portions obtained for CNT were subtracted from the respective charge of the composite electrode (Table 2). It was clear that most of the capacitive portion in the composite electrode was from the CpLum layer which contributed more than 2 times the capacitive charge storage over CNT. In this case, a $4.5 \mathrm{~nm}$ CpLum layer added a

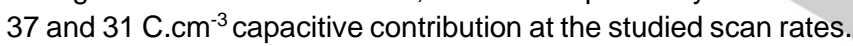
The pure CpLum contributed and maintained about $70 \%$ of overall charge through faradaic processes at both scan rates. This also suggested that the CpLum layer had a synergistic interaction with CNT, and CpLum-CNT is a promising electrode material for ECs.

The high rate capability of the optimized CpLum-CNT composite electrode was further tested and compared to bare CNT at various scan rate between $15 \mathrm{mV} . \mathrm{s}^{-1}$ and $1 \mathrm{~V} . \mathrm{s}^{-1}$ (Figure 9). At a higher scan rate of $1 \mathrm{~V} . \mathrm{s}^{-1}$, both CpLum-CNT and bare CNT retained about $60 \%$ of charge. However, the charge stored in the composite was still $3.5 \mathrm{X}$ of the bare CNT $\left(44 \mathrm{C} . \mathrm{cm}^{-3}\right.$ vs $13 \mathrm{C.cm}$ $\left.{ }^{3}\right)$. The decrease of the total charge can be explained by both ohmic loss and the low accessibility to reactive sites from the bulk diffusion-controlled processes at high scan rate ${ }^{[2 b]}$. In this case, most of the charges were primarily from surface redox processes. Nonetheless, the coulombic efficiency remained constant at $100 \%$ for both CpLum-CNT and bare CNT (Figure 9a). This reflects the good reversibility of the charge and discharge processes, due to the favorable carbon-polymer interaction enabling the formation of a highly stable composite electrode (Figure 2c).
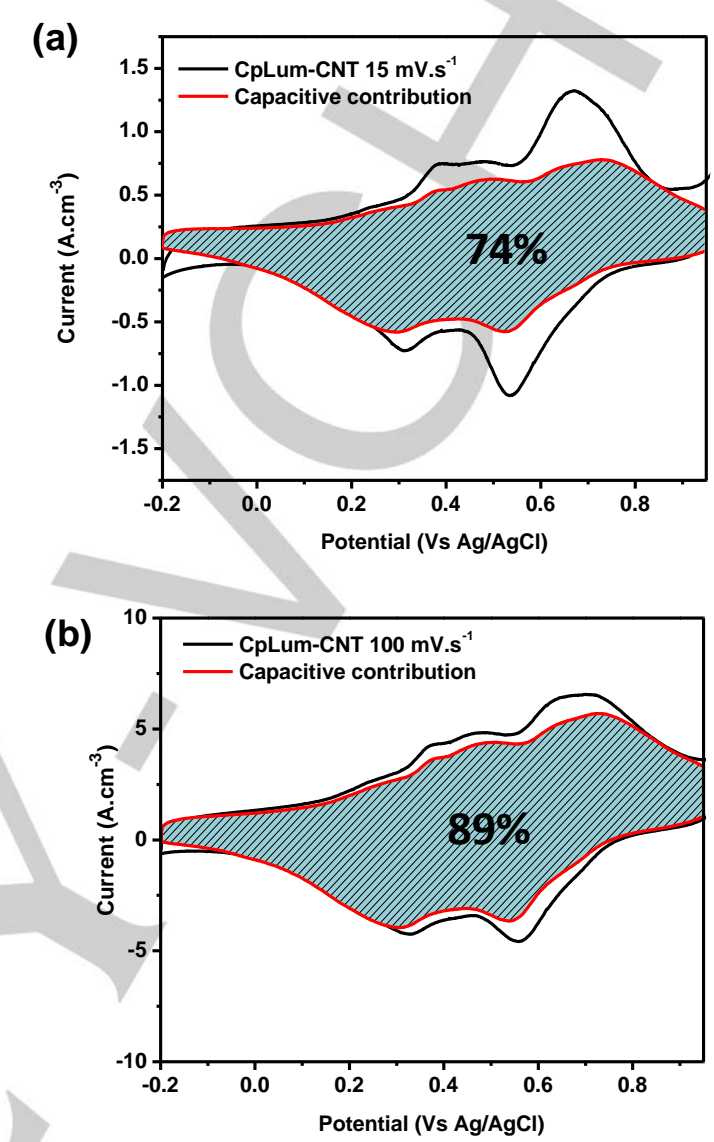

Figure 8. Estimated Capacitive distribution of CpLum-CNT at a) $15 \mathrm{mV} . \mathrm{s}^{-1}$ and b) $100 \mathrm{mV} . \mathrm{s}^{-1}$.

Table 2. Summary of the capacitive and diffusion-controlled contribution for CpLum-CNT, CNT, and CpLum at $15 \mathrm{mV} . \mathrm{s}^{-1}$ and $100 \mathrm{mV} . \mathrm{s}^{-1}$

\begin{tabular}{|c|c|c|c|c|c|c|}
\hline & \multicolumn{3}{|c|}{$15 \mathrm{mV} \cdot \mathrm{s}^{-1}$} & \multicolumn{3}{|c|}{$100 \mathrm{mV} \cdot \mathrm{s}^{-1}$} \\
\hline & $\begin{array}{c}\text { CpLum- } \\
\text { CNT }\end{array}$ & CNT & CpLum & $\begin{array}{c}\text { CpLum- } \\
\text { CNT }\end{array}$ & CNT & CpLum \\
\hline $\begin{array}{l}\text { Charge } \\
\left(\text { C.cm }{ }^{-3}\right)\end{array}$ & 73 & 21 & 52 & 51 & 15 & 36 \\
\hline $\begin{array}{c}\text { Capacitive } \\
\text { contribution } \\
\left(\text { C. } \mathrm{cm}^{-3}\right)\end{array}$ & 54 & 17 & 37 & 45 & 14 & 31 \\
\hline $\begin{array}{l}\text { Diffusion- } \\
\text { controlled } \\
\text { contribution } \\
\left(\mathrm{C} . \mathrm{cm}^{-3}\right)\end{array}$ & 19 & 5 & 14 & 6 & 2 & 4 \\
\hline
\end{tabular}


To further assess the performance of the composite electrodes for ECs application, their cycle life was tested using CV at $1 \mathrm{mV} . \mathrm{s}$ ${ }^{1}$ (Figure 9b)). Both bare CNT and CpLum-CNT maintained a good cycling stability with only $5 \%$ loss in charge storage after 4000 cycles. This good cycling performance can be attributed to three factors: 1) the excellent reversibility of the redox processes; 2 ) the $\pi$-conjugated systems comprised of $B z$ and $Q$ rings allowing the formation of resonant structures and stabilizing the chemical structure of CpLum during the potential cycling ${ }^{[2 b]}$; and 3) good bonding between CpLum and CNT. Previous work on electropolymerized luminol deposited on graphene also supported these notions ${ }^{[3 a]}$.
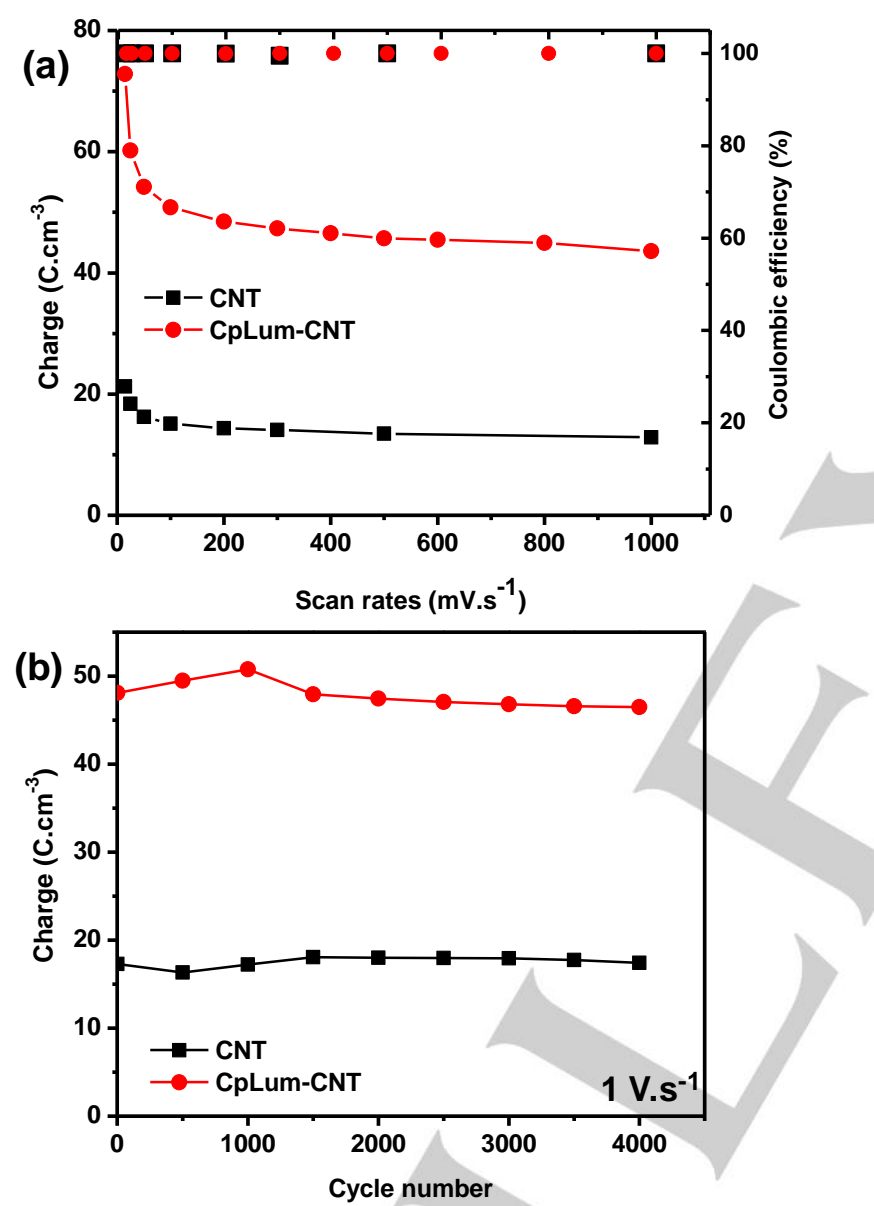

Figure 9. Charge and storage efficiency vs scan rate from $15 \mathrm{mV} \cdot \mathrm{s}^{-1}$ to 1000 $\mathrm{mV} . \mathrm{s}^{-1}$, and b) cycle life at $1 \mathrm{~V} . \mathrm{s}^{-1}$ for bare CNT and CpLum-CNT.

\section{Conclusions}

A composite electrode was developed via in-situ chemical polymerization of luminol (CpLum) on CNT. The coverage of polymerization was tracked by scanning electron microscopy, and a maximum thickness of $4.5 \mathrm{~nm} \pm 1.5 \mathrm{~nm}$ was obtained. DFT analysis revealed that the luminol monomers have a preferred flat orientation before polymerization. The surface chemistry of the
CpLum-CNT composite was analyzed using XPS, where the nitrogen content reached about ca.9\% over bare CNT. The electrochemical analyses of the composite electrode revealed that the optimal polymerization lead to 3.5 times increase in charge storage over bare CNT substrate. The quantification of the charge storage contribution of each component in the composite revealed that the capacitive contribution was mostly due to pseudocapacitance introduced by the thin polymer layer. The CpLum layer on CNT provided $70 \%$ of the total capacitive charge and maintained such contribution at both slow and high scan rate. CpLum-coated carbon electrode is promising for ECs with good charge storage/delivery, high rate performance, and good cycle life.

\section{Experimental Section}

\section{Materials}

Luminol monomer, dimethyl sulfoxide (DMSO $98 \%$ ) solvent, and ammonium persulfate $\left(\left(\mathrm{NH}_{4}\right)_{2} \mathrm{~S}_{2} \mathrm{O}_{8}\right)$ oxidizing agent were purchased from Alfa Aesar and Aldrich, respectively. All chemicals were used as received. Polytetrafluoroethylene (PTFE) 60 wt \% dispersion in $\mathrm{H}_{2} \mathrm{O}$ was purchased from Aldrich. The multiwalled carbon nanotube (CNT) powder was purchased from Cheap Tubes Inc.

\section{Preparation of CNT films}

The CNTs were made into films similar to the method reported in previous studies [10]: $0.4 \mathrm{~g}$ of CNT powder mixed with $15 \mathrm{mg}$ of PTFE equivalent to $4 \mathrm{wt} \% .2 \mathrm{~mL}$ of isopropyl alcohol (IPA) was added to the mixture to form a paste. The CNT paste was then placed in a rolling system to form $4 \mathrm{~cm}$ $x 3 \mathrm{~cm}$ films with a thickness of $100 \mu \mathrm{m}$.

\section{Composite fabrication and optimization}

In-situ polymerization of luminol on CNT films, illustrated in Figure 1, was conducted as follows: (1) placing the CNT films in $20 \mathrm{~mL}$ of water-DMSO mixture (9:1); (2) adding $0.35 \mathrm{~g}$ of luminol to the water-solvent mixture; (3) adding $0.19 \mathrm{~g}$ of $\left(\mathrm{NH}_{4}\right)_{2} \mathrm{~S}_{2} \mathrm{O}_{8}$ to the mixture to initiate the polymerization on the CNT films. The films were soaked in the reaction solution and removed after 15,60 , and 180 min of reactions, and then rinsed thoroughly with DI water

\section{Materials characterizations}

The CpLum-modified CNT composite electrodes (referred to CpLum-CNT) were characterized using cyclic voltammetry (CV), scanning electron microscopy (SEM), Raman spectroscopy, and X-ray photoelectron spectroscopy (XPS). The SEM micrographs were obtained using a Hitachi UHR-SEM SU5000 microscope. The Raman spectra were recorded between 500 and $3500 \mathrm{~cm}^{-1}$, with a Horiba XploRA PLUS Raman microscope. The wavelength of the laser was set to $532 \mathrm{~nm}$, with a diffraction grating of 1200 grooves $/ \mathrm{mm}$. The surface chemistry of bare CNT and the composite films were studied utilizing an XPS Thermo Fisher Scientific K-a, monochromated AI X-ray source over 20 scans with a spot size of $400 \mu \mathrm{m}$ and an energy step size of $0.1 \mathrm{eV}$.

The CV was carried out in a three-electrode cell in $1 \mathrm{M}$ sulphuric acid $\left(\mathrm{H}_{2} \mathrm{SO}_{4}\right)$ under ambient conditions using a Princeton Applied Research VersaSTAT 3 potentiostat. The working electrode, a cavity microelectrode (CME) with a volume of $8.19 \times 10^{-6} \mathrm{~cm}^{3}$, was loaded with the active materials [11]. The counter and reference electrodes consisted of Pt mesh and silver-silver chloride $(\mathrm{Ag} / \mathrm{AgCl})$ electrodes, respectively. All electrochemical measurements were repeated a minimum of 5 times for each deposition condition with good reproducibility. 


\section{Density Functional Theory (DFT) calculations}

All of the computational results presented in this work were based on DFT calculations. The calculations were performed with the Vienna Ab initio Simulation Package (VASP) ${ }^{[12]}$ using Bayesian error estimation functional with van der Waals correlation (BEEF-vdW) ${ }^{[13]}$. A large diameter of the carbon nanotubes $(\sim 23 \mathrm{~nm})$ leads to very small local curvature of the nanotubes, which has a negligible impact on the electronic interaction between the nanotube and luminol. Therefore, the nanotubes were modelled using graphene sheets in studying the adsorption properties of luminol on carbon nanotubes. A 9X9 supercell was used to model graphene, which corresponds to 162 carbon atoms per graphene layer. The adsorption energy of luminol was studied on one- and two-layer graphene. The supercell had lengths of $22.2 \AA$ along the lateral directions and $30 \AA$ along the vertical direction, which was sufficiently large to avoid significant interaction with its periodic images. The plane-wave cutoff of $500 \mathrm{eV}$ was used with a gamma-point $k$-grid, and the atomic positions were fully relaxed such that all the forces were smaller than $0.02 \mathrm{eV} / \mathrm{A}$.

\section{Acknowledgements}

We thank the Natural Sciences and Engineering Research Council of Canada (NSERC) Discovery RGPIN-2016-06219 and Strategic grant 2100-120694 for the financial support. Jeanne N'Diaye would like to thank the Fond de Recherche Nature et Technologie du Québec (FRQNT) for the PhD scholarship. We would like to thank the Ontario Centre for Characterization of Advanced Materials (OCCAM) for the XPS analysis and SEM imaging.

Keywords: Polyluminol • In-situ oxidative polymerization • DFT • electrochemical capacitors $\cdot$ charge contribution

[1] a) A. G. Pandolfo, A. F. Hollenkamp, Journal of Power Sources 2006 157, 11-27; b) E. Frackowiak, F. Béguin, Carbon 2001, 39, 937-950; c) Z. Tan, G. Chen, Y. Zhu, in Nanocarbons for Advanced Energy Storage, Wiley-VCH Verlag GmbH \& Co. KGaA, 2015, pp. 211-225; d) K. Gopalakrishnan, A. Govindaraj, C. N. R. Rao, in Nanocarbons for Advanced Energy Storage, Wiley-VCH Verlag GmbH \& Co. KGaA, 2015, pp. 227-252; e) C. Liu, G. Han, Y. Chang, Y. Xiao, M. Li, W. Zhou, D. Fu, W. Hou, ChemElectroChem 2016, 3, 323-331.

[2] a) A. Kausar, Journal of Macromolecular Science, Part A 2017, 54, 640653; b) V. C. Aiping Yu, Jiujun Zhang, Electrochemical Supercapacitors for Energy Storage and Delivery Fundamentals and Applications, CRC Press ed., 2013; c) A. J. Stevenson, D. G. Gromadskyi, D. Hu, J. Chae, L. Guan, L. Yu, G. Z. Chen, in Nanocarbons for Advanced Energy Storage, Wiley-VCH Verlag GmbH \& Co. KGaA, 2015, pp. 179-210; d) H. Choi, K.-J. Ahn, Y. Lee, S. Noh, H. Yoon, Advanced Materials Interfaces 2015, 2, 1500117.

[3] a) H. Heli, A. Parsa, N. Sattarahmady, Journal of Electroanalytical Chemistry 2015, 751, 15-22; b) Y. Li, X. Zhao, Q. Xu, Q. Zhang, D. Chen, Langmuir 2011, 27, 6458-6463.
[4] a) M. Genovese, K. Lian, ACS Applied Materials \& Interfaces 2016, 8, 19100-19109; b) M. Genovese, K. Lian, Current Opinion in Solid State and Materials Science 2015, 19, 126-137; c) Y.-T. Chang, K.-C. Lin, S.M. Chen, Electrochimica Acta 2005, 51, 450-461; d) S.-M. Chen, Y.-H. Fa, Journal of Electroanalytical Chemistry 2004, 567, 9-17.

[5] a) A. Ghosh, S. Mitra, ChemElectroChem 2018, 5, 159-165; b) E. Tomšík, I. Ivanko, O. Kohut, J. Hromádková, ChemElectroChem 2017, 4, 28842890.

[6] H. Roghani-Mamaqani, V. Haddadi-Asl, M. Salami-Kalajahi, Polymer Reviews 2012, 52, 142-188.

[7] a) H. Cui, W. Wang, C.-F. Duan, Y.-P. Dong, J.-Z. Guo, Chemistry - A European Journal 2007, 13, 6975-6984; b) J. Shu, W. Wang, H. Cui, Chemical Communications 2015, 51, 11366-11369; c) Y. He, D. Liu, X. He, H. Cui, Chemical Communications 2011, 47, 10692-10694; d) H. Dai, Y. Lin, G. Xu, L. Gong, C. Yang, X. Ma, G. Chen, Electrochimica Acta 2012, 78, 508-514; e) G.-F. Zhang, H.-Y. Chen, Analytica Chimica Acta 2000, 419, 25-31; f) A. Sassolas, L. J. Blum, B. D. Leca-Bouvier, Sensors and Actuators B: Chemical 2009, 139, 214-221; g) C. H. Wang, S. M. Chen, C. M. Wang, Analyst 2002, 127, 1507-1511.

[8] S.-M. Chen, K.-C. Lin, Journal of Electroanalytical Chemistry 2002, 523, 93-105.

[9] a) M. Sathiya, A. S. Prakash, K. Ramesha, J. M. Tarascon, A. K. Shukla, Journal of the American Chemical Society 2011, 133, 16291-16299; b) V. Augustyn, P. Simon, B. Dunn, Energy \& Environmental Science 2014, 7, 1597-1614; c) Z. Chen, H. Li, X. Lu, L. Wu, J. Jiang, S. Jiang, J. Wang, H. Dou, X. Zhang, ChemElectroChem 2018, 5, 1516-1524.

[10] a) M. Genovese, Y. W. Foong, K. Lian, Journal of The Electrochemical Society 2015, 162, A5041-A5046; b) J. N'Diaye, K. Lian, NanoStructures \& Nano-Objects 2018, 15, 173-179.

[11] C. Portet, J. Chmiola, Y. Gogotsi, S. Park, K. Lian, Electrochimica Acta 2008, 53, 7675-7680.

[12] a) G. Kresse, J. Furthmüller, Computational Materials Science 1996, 6, 15-50; b) G. Kresse, J. Furthmüller, Physical Review B 1996, 54, 1116911186; c) G. Kresse, J. Hafner, Physical Review B 1994, 49, 1425114269 ; d) G. Kresse, J. Hafner, Physical Review B 1993, 47, 558-561.

[13] J. Wellendorff, K. T. Lundgaard, A. Møgelhøj, V. Petzold, D. D. Landis, J. K. Nørskov, T. Bligaard, K. W. Jacobsen, Physical Review B 2012, 85, 235149.

[14] B. Yi, R. Rajagopalan, H. C. Foley, U. J. Kim, X. Liu, P. C. Eklund, Journal of the American Chemical Society 2006, 128, 11307-11313.

[15] H. Athalin, S. Lefrant, Journal of Raman Spectroscopy 2005, 36, 400408.

[16] J. N'Diaye, K. Lian, Journal of Electroanalytical Chemistry 2019.

[17] a) S. Golczak, A. Kanciurzewska, M. Fahlman, K. Langer, J. J. Langer, Solid State lonics 2008, 179, 2234-2239; b) M. M. Mahat, D. Mawad, G. W. Nelson, S. Fearn, R. G. Palgrave, D. J. Payne, M. M. Stevens, Journal of Materials Chemistry C 2015, 3, 7180-7186.

[18] Y. Y. Smolin, K. L. Van Aken, M. Boota, M. Soroush, Y. Gogotsi, K. K. S. Lau, Advanced Materials Interfaces 2017, 4, 1601201.

[19] a) J. Wang, J. Polleux, J. Lim, B. Dunn, The Journal of Physical Chemistry C 2007, 111, 14925-14931; b) H.-S. Kim, J. B. Cook, S. H. Tolbert, B. Dunn, Journal of The Electrochemical Society 2015, 162, A5083-A5090; c) J. B. Cook, H.-S. Kim, T. C. Lin, C.-H. Lai, B. Dunn, S. H. Tolbert, Advanced Energy Materials 2017, 7, 1601283. 


\section{WILEY-VCH}

\section{ARTICLE}

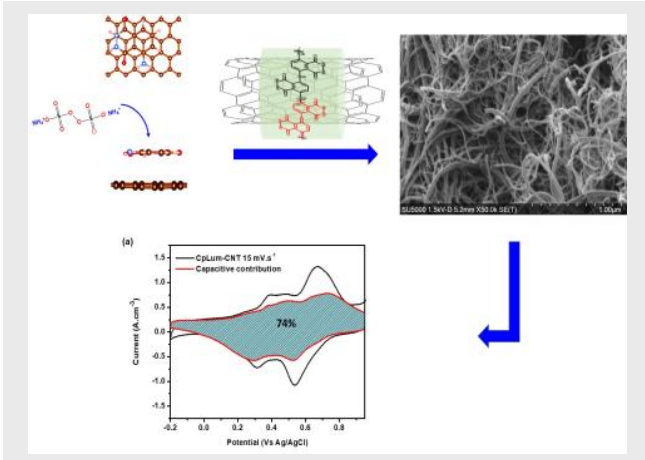

Jeanne N'Diaye, Jin Hyun Chang, and Keryn Lian

\section{Page No. - Page No.}

Title: Stability and charge storage

Polyluminol (CpLum) is polymerized on CNT, where the luminol monomers prefer to be horizontally orientated on the CNT substrate. The CpLum wrap around the individual nanotubes giving a highly stable composite with increased charge storage. The polymer contributes for most of charge storage process via pseudocapacitance.

[a] J. N'Diaye, Prof K. Lian

Materials Science and Engineering

University of Toronto

184 College St, Toronto, Ontario, M5S 3E4, Canada

E-mail: Jeanne.ndiaye@mail.utoronto.ca, keryn.lian@utoronto.ca

[b] J. H. Chang

Department of Energy Conversion and Storage

Technical University of Denmark

DK-2800 Kgs. Lyngby, Denmark Address 2

E-mail: jchang@dtu.dk

Supporting information for this article is given via a link at the end of the document. 